\title{
Physicochemical characteristics of food and the digestion of starch and dietary fibre during gut transit
}

\section{By J. A. Robertson, AFRC Institute of Food Research, Norwich Laboratory, Colney Lane, Norwich NR4 7UA}

Food consists of a complex group of substances that differ in chemical composition and physical structure. Collectively these substances form a matrix and it is the behaviour of this matrix which determines the digestibility, the rate and extent of nutrient release, from a food during normal gut transit. In the process of digestion both chemical and physical degradation of food occurs.

Chemical degradation allows nutrient release from food, and nutrient values provided in food tables are derived by chemical analysis of food and must be combined with a knowledge of the potential nutrient availability in a particular food if a proper understanding is to be gained of nutrient utilization by the body. Nutrient availability, applied to mean nutrients in a form suitable for digestion, absorption and utilization, has been extensively studied in relation to minerals and especially iron (Hallberg et al. 1986). However, less is known about availability of other nutrients, as can be illustrated from a consideration of 'complex-carbohydrate' digestion. Digestion and rate of absorption of carbohydrate has been shown to be important in the control of glycaemia (Crapo et al. 1980; Simpson et al. 1981; Thorne et al. 1983) and physical form of food is an important determinant of digestion rate. The effect of physical structure, however, is difficult to predict and can act to either enhance or restrict nutrient release. For example, the action of rennin on milk protein changes milk from an emulsion to a gel and enhances digestibility, but the presence of lignin in forage and fibre restricts accessibility of cell-wall polysaccharides to microbial degradation.

Thus the extent and rate of digestion during gut transit is a function of the complex interaction between physical and chemical properties of a food matrix. Measurements of physical properties of foods (Table 1) have been made in an attempt to determine their effect on digestion. However, as will be shown for starch and fibre digestion, the results often depend on methods used and may conflict with digestion results determined in vivo.

\section{Digestibility}

Starch digestion. Starch is a mixture of amylose and amylopectin and during transit through the small intestine these are hydrolysed to release mainly maltose and glucose. Depending on the starch source, the rate and extent of digestion varies (Fig. 1). The rapid, and effectively complete, digestion of purified potato starch contrasts with the slow and incomplete digestion of legume starches. The extent of digestion also differs between starch sources. Purified potato starch was effectively completely digested but starch in potato was only $70 \%$ digested under in vitro conditions. Other foods tested also showed incomplete starch digestion which suggests some physical inaccessibility to digestion in the food. Fibre content was related to rate of digestion to some extent (Gee $\&$ Johnson, 1985), the implication being that the presence of fibre and its particulate and viscous nature was impeding enzyme access to the food matrix.

The method of food preparation may also influence the digestion of a food. For starch foods, processing conditions can affect digestibility through the formation of retrograde starch (Dreher et al. 1984; Berry, 1986). This starch is resistant to amylase activity in the 
Table 1. Physicochemical properties of food important in digestion

Property
Digestibility
Particle size
Viscosity
Hydration
Porosity
Absorption, ion exchange
Solubility

\author{
Influencing \\ Extent of food degradation \\ Surface area available for digestion \\ Digesta flow and nutrient availability \\ Flow and mixing of digesta \\ Nutrient availability \\ Nutrient availability \\ Viscosity, mixing, availability
}

small intestine and passes undigested to the hind-gut where it is fermented and is, therefore, analogous to fibre in dietary effect, although chemically indistinguishable from starch (Englyst \& MacFarlane, 1986).

Therefore, although chemistry can predict probable digestibility in the small intestine, as shown for starch, actual digestibility will depend on food source, preparation methods as well as an individual's digestion characteristics, such as degree of mastication and transit time through the small intestine.

This can be illustrated from experiments using ileostomy patients fed on samples of banana containing different amounts of starch (Englyst \& Cummings, 1986) where it was found that increasing the amount of starch fed, by feeding increasingly unripe bananas, increased the amount of carbohydrate recovered in the ileostomy fluid. This carbohydrate was mainly starch and dextrins resulting from the partial digestion of starch and showed that banana starch was incompletely digested in the small intestine. The starch was given as raw starch, which is less digestible than cooked or gelatinized starch. Similar experiments using cereal starches (Englyst \& Cummings, 1985) and potato (Englyst \& Cummings, 1987) showed starch to be almost completely digested in the small intestine of ileostomy subjects. However, previous investigations of breath hydrogen production following high-starch cooked meals in normal subjects have suggested that starch reaches the hind-gut undigested (Anderson et al. 1981), and it may be that digestion has become 'more efficient' in ileostomy patients.

Fibre digestion. Fibre is mainly cell-wall material, composed of cellulose, hemicellulose, uronic acids and lignin and is resistant to digestion by non-microbial enzymes

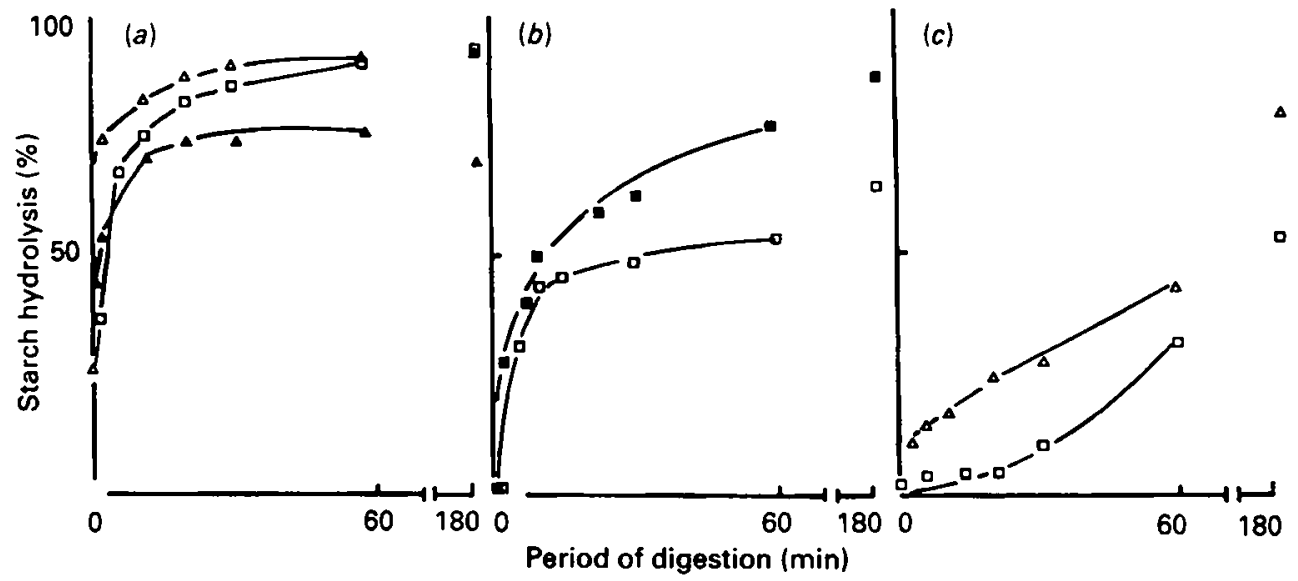

Fig. 1. In vitro digestion of starch. (a) (D), Potato starch; $(\Delta)$, maize starch; $(\Delta)$, potato; $(b)(\square)$, pea (Pisum sativum); $(\square)$, bread; (c) (D), baked beans; $(\Delta)$, lentils. Values at 180 min represent potential digestibility under the conditions used. Adapted from Gee \& Johnson (1985). 


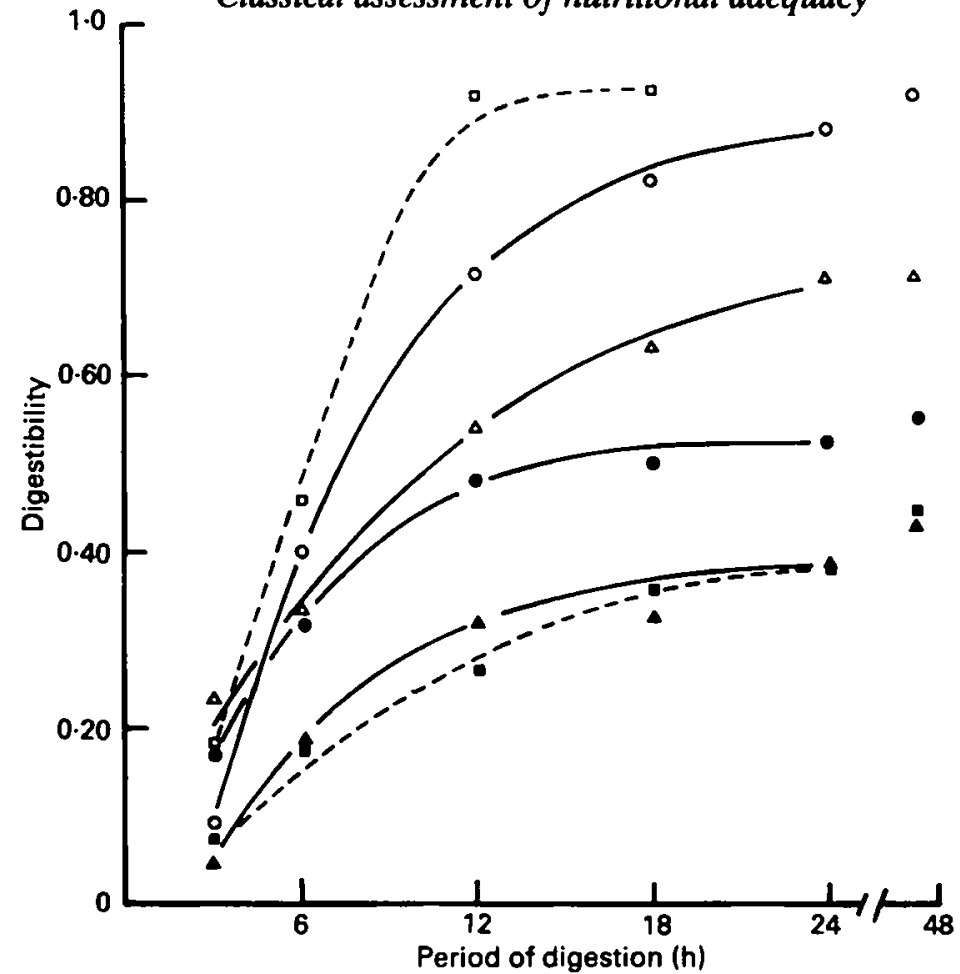

Fig. 2. Digestion of fibre preparations measured in the pig caecum $(0,0, \Delta, \Delta)$ and in the rumen $(\square, \square)$. $(\square, O, \Delta)$, Swede; $(\square, O, \Delta)$, bran; $(\Delta, \Delta)$, ileal digesta. Values at $48 \mathrm{~h}$ represent potential digestibility of each fibre preparation (i.e. $1-$ digestion $48 \mathrm{~h}=$ non-digestible fraction). Adapted from Robertson et al. (1987) and Van Soest (1975).

during gut transit. However, through microbial action fibre can be fermented to fatty acids and made available for absorption. As shown in Fig. 2 the profile of fibre and starch digestion is similar, although the time-interval required for fibre digestion is much longer than that for starch. Fibre degradation, like starch, also varied with source but was always less than $100 \%$, even after extended incubation in the caecum, and hence fibre can be considered to have a limited potential digestibility as shown in Fig. 2.

Interestingly, digestion with rumen organisms (Van Soest, 1975) and in the pig caecum (Robertson et al. 1987) was similar for corresponding fibre sources, although faster for swede with the rumen organisms. This illustrates potential digestibility to be a property of the fibre matrix and not the digestive system. However, differences between fibre sources indicated that chemical composition and structure also affect digestibility and that differences can occur between native fibre and the corresponding material recovered from ileal digesta. The fibre matrix therefore can be modified by transit through the small intestine, although not necessarily digested during transit. Overall loss of uronic acid has also been reported during transit through the pig small intestine (Millard \& Chesson, 1984) and low levels of pectinolytic activity have been found in the pig ileum (Chesson et al. 1985) and also in ileostomy patients (Tasman-Jones \& Holloway, 1983). Some loss of pectic material therefore may occur in the small intestine due to microbial breakdown as well as solubilization.

Physical form can be important in determining potential digestibility (Brice \& Morrison, 1982) as can chemical composition, especially the presence of lignin in forages (Mertens, 1977). Bran used in the experiments with pigs had a relatively high lignin 
Table 2. Composition, digestibility and half-life $\left(\mathrm{t}_{1 / 2}\right)$ of water-insoluble material (WIM) in the pig caecum

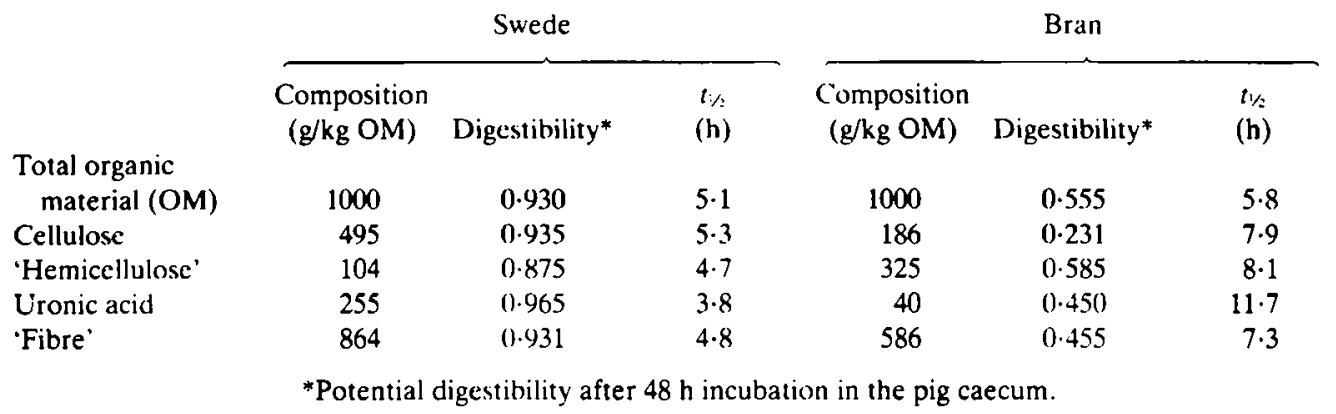

content and a low potential digestibility relative to swede (Table 2). Fibre components in swede were also effectively completely digestible, although the hemicellulose fraction was less digestible than cellulose or uronic acid despite being present at a much lower concentration in the fibre matrix. Conversely, in bran the hemicellulose fraction was most readily degradable, with cellulose and uronic acid showing no significant degradation.

Physical disruption of digesta and solubilization during transit will make material more available for digestion (i.e. increase the rate of digestion) during the relatively rapid transit through the small intestine (3-4 h) by increasing surface area and accessibility to enzyme action. Estimation of rates of digestion usually assume that $100 \%$ digestion is achieved but as shown this is not necessarily so and hence it is more correct to consider rates determined for the potentially digestible fraction of a nutrient.

Rates of digestion, shown as half-life and calculated as rate of digestion of the potentially digestible fraction, confirmed that different components could be degraded at different rates and rate was dependent on fibre source. Differences in the rate of digestion of cellulose between swede and bran also illustrated how a chemically distinct component like cellulose can vary in digestibility, even in its native form, and hence how the use of dietary isolates to investigate digestion can be misleading (Van Soest \& Robertson, 1976).

Similarly, estimation of potential digestibility and rates of digestion in an isolated gut compartment can be misleading, in relation to overall digestion during gut transit, since changing conditions during transit may alter digestibility. Estimation of the overall digestibility of swede and bran fibre during transit showed digestion was always less than the estimated potential digestibility and the effect was not due to transit time (swede $\mathbf{5 5} \mathbf{h}$ transit, bran $49 \mathrm{~h}$ transit). Swede-fibre digestibility during transit was $87 \%$, which was slightly less than that found for cabbage in man (Stephen \& Cummings, 1980) but greater than that found with other vegetables (Williams \& Olmstedt, 1936). However, bran digestibility was $41 \%$, which was greater than other values reported for bran in man (27-30\%) (Williams \& Olmstedt, 1936; Stephen \& Cummings, 1980).

The reasons why potential digestibility may not be realized during gut transit include changing conditions along the gastrointestinal tract and physical barriers to digestion resulting from viscosity and particle size of digesta.

\section{Viscosity}

Viscosity is a measure of resistance to flow and in a food system is related to chemical composition and structure of the food matrix. As digestion proceeds food composition 
and structure change and hence viscosity changes. However, as well as being affected by digestion, viscosity may also influence digestion, as shown by the effect of soya-bean texture during simulated digestion (Robb et al. 1986). Three soya-bean products, a full-fat flour, concentrated protein and textured protein, under simulated gastric digestion, became a slurry, a thick sticky paste and a particulate suspension respectively. No difference in enzymic solubilization was found between the particulate suspension and the slurry but the thick paste was less solubilized. Subsequent simulated ileal digestion showed the paste to remain less solubilized. Thus, although each product was derived from a common source and presumably of equal potential digestibility, differences in texture resulted in differences in rate of digestion. During gut transit, therefore, the thick sticky paste might be less digested than the other two products.

The extent to which viscosity may affect the rate of digestion has been investigated in starchy foods (Gee \& Johnson, 1985). Differences in viscosity were found between starch sources but did not relate to the extent or rate of digestion. The viscosity of extracted potato starch was negligible but for the total potato preparation it was approximately 800 $\mathrm{mPa} / \mathrm{s}$, similar to that of white bread and twice that of baked beans. Viscosity did not appear to be affected by starch concentration, this being constant for each experiment, and the loss of starch did not result in a proportionate loss in viscosity. Simulated digestion did result in a decrease in viscosity, but final viscosity remained greater than $100 \mathrm{mPa} / \mathrm{s}$, indicating that viscosity could be important in the control of nutrient absorption if the property is effective during gut transit.

Viscosity during transit has been investigated using water-soluble guar gum added to a diet given to rats (Blackburn \& Johnson, 1981). At low levels of guar gum in the diet, stomach contents were watery and viscosity of ileal digesta was low. Increasing the amount of guar gum led to formation of a solid pellet of digesta in the stomach and an increase in viscosity of ileal contents proportional to the level of guar gum fed. Similar results have been reported for the pig small intestine and in relation to possible effects of viscosity on gastric emptying (Rainbird \& Low, 1986).

Viscosity of digesta could be important in controlling accessibility of the substrate to digestion through reduced flow and mixing characteristics. A reduced rate of digestion, measured as enzyme inhibition in the presence of fibre preparations, has been demonstrated (Schneeman, 1978; Dunaif \& Schneeman, 1981; Ikeda \& Kusano, 1983) but results are inconsistent, possibly due to methods of fibre preparation, but more probably due to residual anti-nutritional factors present in the fibre (Leiner \& Kakade, 1980). However, pectin- and xylan-fibre isolates have each been shown to inhibit trypsin activity in vitro by non-competitive inhibition (Ikeda \& Kusano, 1983). The kinetics of the inhibition indicated reduced availability of the substrate to tryptic digestion, but whether this was due to viscosity, adsorption or ion-exchange phenomena was not determined. Pectin and xylan would each increase viscosity but the ability of fibre to adsorb material, as shown for bile salts (Story \& Kritchevsky, 1975; Eastwood \& Mowbray, 1976; Anon., 1977), and the ion-exchange properties, as shown for metal cations (Eastwood \& Mitchell, 1976, James et al. 1978), could also affect enzyme-substrate interaction.

\section{Particle size}

Particle size will affect availability of nutrients for digestion. Mastication of food will reduce the particle size of solid food and effectively increase the surface area available for digestion. During transit, particles can change in size, shape, porosity and number. The outcome is generally to increase the surface area available and accessibility of the particles to digestion. 

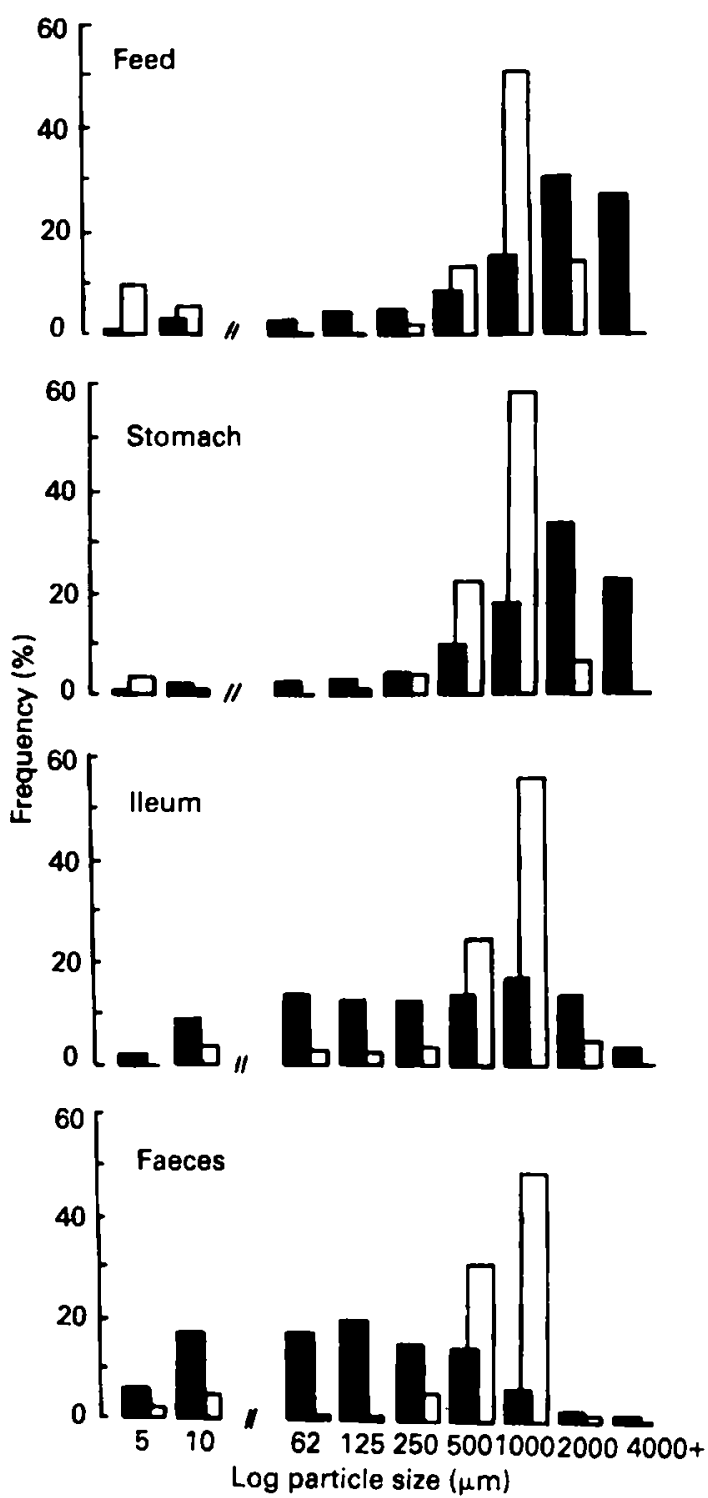

Fig. 3. Particle-size distribution of cereal (bran, $\square$ )- and vegetable-fibre (swede, $\square$ )-based diets during gut transit in pig. Particle size distribution was determined by wet sieving through a series of sieves from $4000 \mu \mathrm{m}$ to $5 \mu \mathrm{m}$ mesh as shown. Results are expressed as the proportion of water-insoluble material recovered from each sieve. For swede, total water-insoluble material in feed represented approximately $400 \mathrm{~g} / \mathrm{kg}$ total diet and for bran approximately $750 \mathrm{~g} / \mathrm{kg}$ total diet. Faecal material was more than $900 \mathrm{~g}$ water-insoluble material $/ \mathrm{kg}$ with an apparent digestibility of 0.80 of the original diet in swede and 0.55 of the original diet in bran.

Monitoring particle-size-distribution changes of swede and bran during transit in the pig (Fig. 3) showed that particle size was reduced in swede anterior to the terminal ileum and further reduced in the hind-gut, whereas little change was apparent in bran. Particle-size reduction was not due to mastication, the median particle size of feed and stomach contents being similar. Since the particles were mainly cell-wall material and hence considered indigestible in the small intestine, solubilization and physical disruption during transit, and not digestion, must be responsible for the reduction. 
Particle size in bran was also reduced anterior to the terminal ileum, but the reduction was modest and probably limited to loss of starch granules and disruption of endosperm cells. The greatest change in bran occurred in the hind-gut, but was only indirectly a change in size. In feed, bran appeared as a flaky material, but in faeces was recovered as loosely coiled cylindrical particles. This reduced the gross dimensions of the particles resulting in an apparent reduction in size. Microscopy of recovered bran in faeces showed starch granules and endosperm cells to be absent and aleurone-layer cells to be disrupted, as also observed in man (Dintzis et al. 1979; Moss \& Mugford, 1986). This was also ascribed to particle degradation rather than changes caused by cooking (Dintzis et al. 1979). Changes in shape in swede particles were not apparent, in feed appearing as 'irregular spheres' and in faeces as small 'irregular spheres' with mainly remnants of epidermis, cuticle and plant vascular tissue residual to the preferential degradation of other plant-cell-wall material, as also found in the rumen (Akin et al. 1974).

Digestion in ruminants also leads to a reduction in particle size as a result of rumination, fermentation and mechanical breakdown through muscular interaction with the rumen wall. During the course of digestion, particles in the rumen become more fragile (Akin, 1979) and hence more easily physically dispersed. Decreasing particle size in the rumen also increases the density of particles (Evans et al. 1973) and thus stratification of particles tends to occur (see Evans et al. 1973), small particles sinking and being passed out of the rumen and larger particles rising and being further subjected to physical breakdown by rumination and prolonged fermentation through increased rumen retention time.

Particle size of the feed is therefore important in ruminant digestion, since it determines the surface area available for digestion and affects residence time in the rumen. It has been suggested that the rate of particle-size reduction may be the rate-limiting step in rumen digestion (Ellis et al. 1979; Mertens \& Ely, 1979), although chemical composition will also affect particle size and the extent of digestion (Ehle et al. 1982). Particle size is unlikely to be the rate-limiting step in non-ruminant digestion although it could affect the rate of digestion by affecting nutrient availability (Kahlon et al. 1986) and, for fibre, could influence colon function and the hydration properties of digesta (Kirwan et al. 1974; Heller et al. 1980; Mongeau \& Brassard, 1982).

\section{Water holding and porosity}

Water is a primary constituent of food. Most of this water is free water and during digestion is used for the mixing of digesta, solubilization and maintenance of nutrients in solution before absorption. The amount of water held by a food is a function of structure and chemical composition (Robertson \& Eastwood, 1981a) and, by the use of suction pressure, can be shown to be loosely held or trapped water (Robertson \& Eastwood, $1981 b$ ). In materials with a 'gel-like' structure water forms an integral part of the matrix (Lewicki et al. 1978) and increasing suction pressure results in a decrease in the amount of water held and a decrease in gel pore size. A decrease in water held (increase in gel concentration) has been shown to reduce the rate of diffusion of glucose from a gel matrix (Blackburn et al. 1984), implying a reduction in pore size within the gel matrix. Pore radius $(r)$ can be related to suction pressure $(\triangle P)$ and surface tension $(s)$ according to the relation (Childs, 1940):

$$
r=\frac{2 s}{\Delta P}
$$

providing a means to investigate pore size distribution within a gel matrix. 

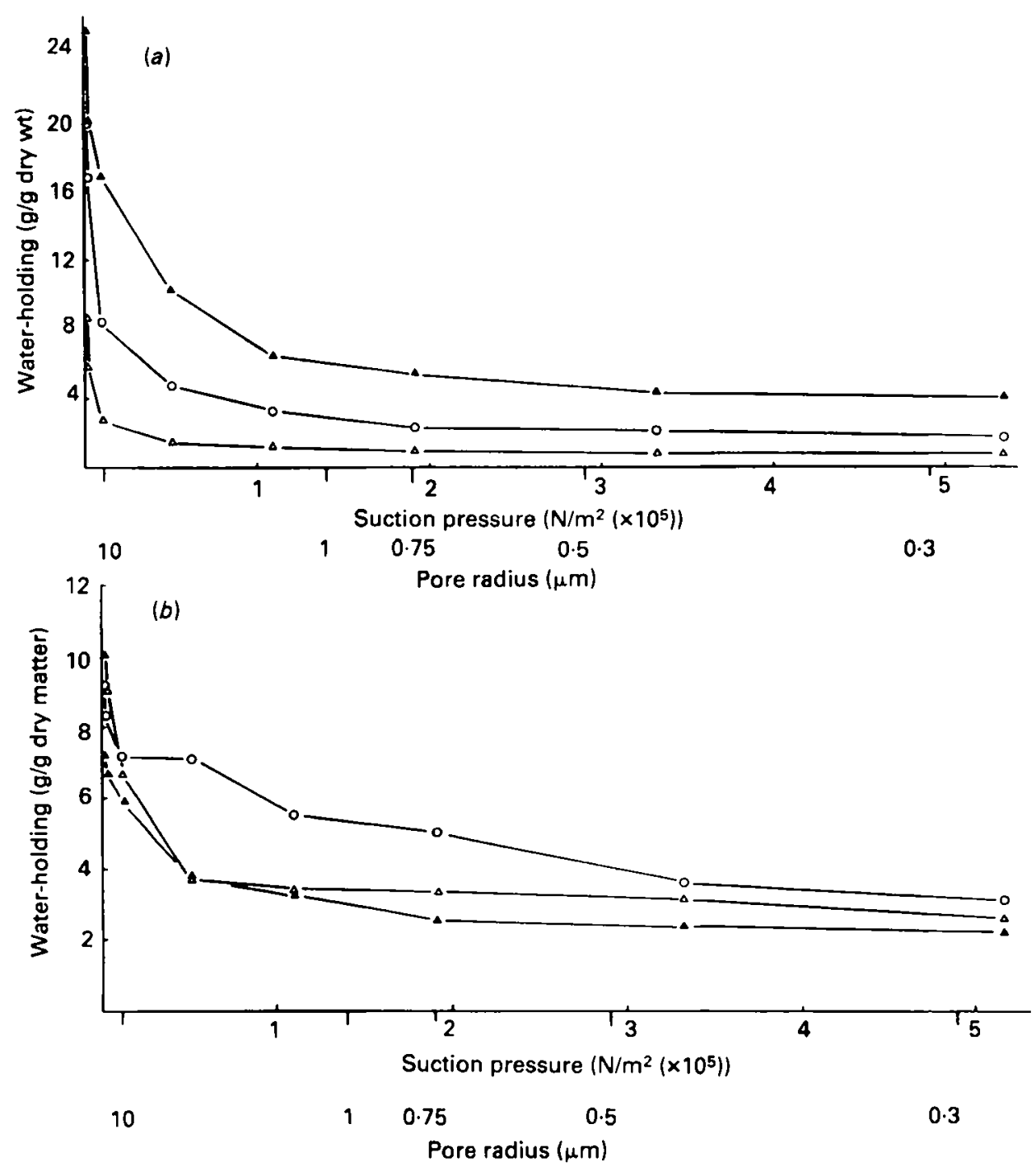

Fig. 4. Effect of suction pressure on water-holding and pore-size distribution in (a) swede and $(b)$ bran water-insoluble materials during gut transit in the pig. $(\Delta)$, Feed; $(O)$, ileal digesta; $(\Delta)$, faeces. Suction pressure and water-holding were measured according to Robertson \& Eastwood (1981b). Pore radius is calculated as $2 s$, where $s$ is surface tension and $\Delta P$ suction pressure.

$$
\overline{\Delta P}
$$

For dietary fibre the rate of water loss was found to depend on fibre source, vegetable fibre being similar to a gel but cereal bran having a distinct and relatively poor water-holding capacity (Robertson \& Eastwood, 1981b). At $2 \mathrm{~atm}\left(2.0265 \times 10^{5} \mathrm{~Pa}\right)$ suction pressure, the suggested equivalent suction pressure across the colonic mucosa (McBurney et al. 1985) water held by different fibre sources was similar. Water held at 2 atm suction pressure by swede insoluble-digesta showed that during transit this changed from $5.6 \mathrm{~g} / \mathrm{g}$ in feed to $2.3 \mathrm{~g} / \mathrm{g}$ in ileal digesta and $0.9 \mathrm{~g} / \mathrm{g}$ in faeces. Corresponding values for bran were $2.1 \mathrm{~g} / \mathrm{g}$ in feed, $5.0 \mathrm{~g} / \mathrm{g}$ in ileal digesta and $3.3 \mathrm{~g} / \mathrm{g}$ in faeces (J. A. Robertson and $\mathrm{A}$. Chesson, unpublished results). Results were consistent with those found for in vitro fibre digestion (McBurney et al. 1985) and correspond to a potential bulking 
(indigestible residue $\times$ residue water-holding) of $0.07 \mathrm{~g} / \mathrm{g}$ in swede and in bran $1.49 \mathrm{~g} / \mathrm{g}$ (McBurney et al. 1985) and illustrates how the bulk and porosity of the food matrix can change during digestion.

Estimation of water-holding in swede and bran digesta samples at different suction pressures and pore size (Fig. 4) showed that a slight increase in suction pressure resulted in a large decrease in water held, corresponding to a loss of loosely-held water from larger pores. At a lower suction pressure water held by swede was greater than that held by bran, but as pressure increased the difference became less, as found previously for different fibre preparations (Robertson \& Eastwood, 1981b).

Water-holding also varied during gut transit. A comparison of water held between 0 and 2 atm suction pressure (i.e. free water or water easily removed from the fibre matrix and representing the pore volume of free water) showed that in swede, pore volume represented by water-holding decreased during transit, but in bran was less in feed than in faeces though greatest in ileal digesta, indicating a changing porosity during transit. How this relates to changes in particle size and shape in bran is uncertain, but when considered in conjunction with digestibility shows that material loss from bran did not result in matrix collapse, whereas in swede material, loss was associated with particle destruction. Thus, during transit, particle digestion can differ between food sources and indicates the importance of considering physical structure in the digestion process.

\section{Conclusion}

Investigation of the physicochemical behaviour of foods during the process of digestion indicates that nutrient availability from food can be less than the amount of nutrient present and hence that measured for inclusion in food tables. This can result in a tendency to overestimate the nutritional value of foods. Ways must therefore be sought to estimate potential availability and nutritional value of food through a better understanding of the physicochemical behaviour of food during digestion, under representative physiological conditions.

The author would like to thank Dr. Ian Johnson for helpful comments during the preparation of this paper.

\section{REFERENCES}

Akin, D. E. (1979). Journal of Animal Science 48, 701-710.

Akin, D. E., Burdick, D. \& Michaels, G. E. (1974). Applied Microbiology 27, 1149-1156.

Anderson, I. H., Levine, A. S. \& Levitt, M. D. (1981). New England Journal of Medicine 304, 891-892.

Anon. (1977). Nutrition Reviews 35, 183-185.

Berry, C. S. (1986). Journal of Cereal Science 4, 301-314.

Blackburn, N. A. \& Johnson, I. T. (1981). British Journal of Nutrition 46, 239-246.

Blackburn, N. A., Redfern, J. S., Jarjis, J., Holgate, A. M., Hanning, I., Scarpello, J. H. B., Johnson, I. T. \& Read, N. W. (1984). Clinical Science 66, 329-336.

Brice, R. E. \& Morrison, I. M. (1982). Carbohydrate Research 101, 93-100.

Chesson, A., Robertson, J. A. \& Richardson, A. J. (1985). Beretring fra Statens Hysdyrbruysforsog 580 , 272-275.

Childs, E. C. (1940). Soil Science 50, 239-252.

Crapo, P. A., Kolterman, O. G., Waldeck, N., Reavan, G. M. \& Olefsky, J. M. (1980). American Journal of Clinical Nutrition 33, 1723-1728.

Dintzis, F. R., Legg, L. M., Deatherage, W. L., Baker, F. L., Inglett, G. E., Jacobs, R. A., Reck, S. J., Murray, J. M., Kleroy, L. M., Sandstead, H. H. \& Sluey, W. C. (1979). Cereal Chemistry 56, $123-127$.

Dreher, M. L., Dreher, C. J. \& Berry, J. W. (1984). CRC Critical Reviews in Food Science and Nutrition 20, 47-71. 
Dunaif, G. \& Schneeman, B. O. (1981). American Journal of Clinical Nutrition 34, 1034-1035.

Eastwood, M. A. \& Mitchell, W. D. (1976). In Fibre in Human Nutrition, pp. 109-130 [G. A. Spiller and R. J. Amen, editors]. New York: Plenum Press.

Eastwood, M. A. \& Mowbray, L. (1976). American Journal of Clinical Nutrition 29, 1461-1466.

Ehle, F. R., Murphy, M. R. \& Clark, J. H. (1982). Journal of Dairy Science 65, 963-971.

Ellis, W. C., Matis, J. H. \& Lascano, C. (1979). Federation Proceedings 38, 2702-2706.

Englyst, H. N. \& Cummings, J. H. (1985). American Journal of Clinical Nutrition 42, 778-787.

Englyst, H. N. \& Cummings, J. H. (1986). American Journal of Clinical Nutrition 44, 42-50.

Englyst, H. N. \& Cummings, J. H. (1987). American Journal of Clinical Nutrition 45, 423-431.

Englyst, H. N. \& MacFarlane, G. T. (1986). Journal of the Science of Food and Agriculture 37, 699-706.

Evans, E. W., Pearce, G. R., Burnett, J. \& Pillinger, S. L. (1973). British Journal of Nutrition 29, 357-376.

Gee, J. M. \& Johnson, I. T. (1985). Journal of Food Science and Agriculture 36, 614-620.

Hallberg, L., Brune, M. \& Rossander, L. (1986). American Journal of Clinical Nutrition 43, $59-67$.

Heller, S. N., Hackler, L. R., Rivers, J. M., Van Soest, P. J., Roe, D. A., Lewis, B. A. \& Robertson, J. (1980). American Journal of Clinical Nutrition 33, 1734-1744.

Ikeda, K. \& Kusano, T. (1983). Cereal Chemistry 60, 260-263.

James, W. P. T., Branch, W. J. \& Southgate, D. A. T. (1978). Lancet i, 638-640.

Kahlon, T. S., Chow, F. I., Hoefer, J. L. \& Betschart, A. A. (1986). Cereal Chemistry 63, $490-493$.

Kirwan, W. O., Smith, A. N., McConnell, A. A., Mitchell, W. D. \& Eastwood, M. A. (1974). British Medical Journal iv, 187-189.

Leiner, I. E. \& Kakade, M. L. (1980). Toxin Constituents of Plant Foodstuffs, 2nd ed. New York: Academic Press.

Lewicki, P. P., Bush, G. C. \& Labuza, T. P. (1978). Journal of Colloid and Interface Science 64, 501-509.

McBurney, M. I., Horvath, P. J., Jeraci, J. L. \& Van Soest, P. J. (1985). British Journal of Nutrition 53, 17-24.

Mertens, D. R. (1977). Federation Proceedings 36, 187-192.

Mertens, D. R. \& Ely, L. O. (1979). Journal of Animal Science 49, 1085-1095.

Millard, P. \& Chesson, A. (1984). British Journal of Nutrition 52, 583-594.

Mongeau, R. \& Brassard, R. (1982). Cereal Chemistry 59, 413-417.

Moss, R. \& Mugford, D. C. (1986). Journal of Cereal Science 4, 171-178.

Rainbird, A. L. \& Low, A. G. (1986). British Journal of Nutrition 55, 87-98.

Robb, P., Williams, D. R., Crews, H. M. \& McWeeny, D. J. (1986). Journal of Food Technology 21, $717-725$.

Robertson, J. A. \& Eastwood, M. A. (1981a). British Journal of Nutrition 45, 83-87.

Robertson, J. A. \& Eastwood, M. A. (1981b). British Journal of Nutrition 46, 247-255.

Robertson, J. A., Murison, S. D. \& Chesson, A. (1987). Journal of Nutrition 117, 1402-1409.

Schneeman, B. O. (1978). Journal of Food Science 43, 634-635.

Simpson, H. C. R., Lousley, S., Geekie, M., Simpson, R. W., Carter, R. D. \& Hockaday, T. D. R. (1981). Lancet 1, 1-5.

Stephen, A. M. \& Cumming, J. H. (1980). Nature 284, 283-284.

Story, J. A. \& Kritchevsky, D. (1975). Nutrition Reports International 11, 161-164

Tasman-Jones, C. \& Holloway, W. D. (1983). In Fibre in Human and Animal Nutrition, pp. 91-93 [G. Wallis and L. Bell, editors]. Wellington: Royal Society of New Zealand.

Thorne, M. J., Thompson, L. U. \& Jenkins, D. J. A. (1983). American Journal of Clinical Nutrition 38, 481-488.

Van Soest, P. J. (1975). In Proceedings of 4th International Symposium on Ruminant Physiology, pp. 351-365 [I. W. McDonald and A. C. I. Warner, editors]. Armidale, Australia: University of New England Publishing Unit.

Van Soest, P. J. \& Robertson, J. B. (1976). In Dietary Fibre, Proceedings of the Nutrition Society of Canada, pp. 351-365 [W. W. Hawkins, editor]. Nova Scotia: Nutrition Society of Canada.

Williams, R. D. \& Olmstedt, W. H. (1936). Journal of Nutrition 11, 433-449. 